\title{
15
}

\section{Treatment Interventions II: Working with the Mind}

\begin{abstract}
Cognitive and other psychological processes on the mind level of operations are amenable to conscious manipulation, and they provide a therapeutic window for change. These psychological processes can have a powerful top-down effect, with the capacity to contribute to the child's efforts to regulate her stress system, her body more generally, and her thoughts, feelings, and beliefs. In this chapter we briefly discuss a variety of interventions on the mind level of operations. These interventions are helpful for interrupting illness-promoting psychological processes that activate the stress system and that trigger or maintain functional somatic symptoms, and also for fostering health-promoting psychological processes that down-regulate the stress system and abate functional somatic symptoms.
\end{abstract}

In this chapter we turn to regulation strategies that involve working with the mind, which is to work from the top down. As we saw

Electronic supplementary material The online version of this chapter

(https://doi.org/10.1007/978-3-030-46184-3_15) contains supplementary material, which is available to authorized users.

(C) The Author(s) 2020

K. Kozlowska et al., Functional Somatic Symptoms in Children and Adolescents, Palgrave Texts in Counselling and Psychotherapy, https://doi.org/10.1007/978-3-030-46184-3_15 
in Chapter 12, cognitive and other psychological processes-those involving the mind-have a powerful top-down effect, with the capacity both to activate and to down-regulate the stress system. Topdown interventions are meant to address ongoing processes that do not necessarily match the actual degree of threat that a child (including adolescent) is exposed to. In some cases, though, the child is actually at risk of harm-for example, from abuse within the family or from cyberbullying - in which case the thought processes relating to threat may match the actual degree of threat. In that case, addressing the threat via the appropriate protective intervention is the proper course of treatment. Assuming, however, that the child or adolescent is safe in her actual family and school contexts and that real-life threats do not need to be addressed, top-down mind interventions can be used alongside interventions on other system levels to down-regulate the stress system.

Top-down emotion-regulation strategies are those in which the child utilizes intentional efforts to increase her attention and awareness capacities for better control of thoughts and feelings (Guendelman et al. 2017). From the neuroscience perspective, successful implementation of top-down self-regulation strategies involves activation of the executive control system and deactivation of brain regions that are part of the brain stress systems and that play a role in regulating physiological arousal (Guendelman et al. 2017). The executive control system involves a network of regions-midline frontal areas (anterior cingulate and ventral prefrontal cortex), lateral prefrontal cortex, and posterior brain regions (posterior cingulate cortex and parts of the parietal cortex) - that operate as a unit on any task involving high-level cognition (Posner 2012; Williams 2016).

\section{Expectations and the Placebo Effect}

The child's and family's expectations, as well as the placebo effect, play an important part in the child's therapeutic response to each treatment intervention and to the treatment intervention as a whole (Benedetti 2013; Koyama et al. 2005). As noted by Tor Wager and Lauren Atlas (2015), all treatments are 
delivered in a context that includes social and physical cues, verbal suggestions and treatment history. This context is actively interpreted by the brain and can elicit expectations, memories and emotions, which in turn can influence health-related outcomes in the brain and body. Placebo effects are thus brain-body responses to context information that promote health and well-being. (Wager and Atlas 2015, p. 2)

Consequently, the total therapeutic effect of the systemic intervention for functional somatic symptoms includes both the neurophysiological effects from the actual treatments and the (neurophysiological) placebo effect. The expectations held by the child and the family-which are shaped by the conversations and non-verbal communications that take place between the child, family, and the clinician (clinical team)_are a fundamental component of treatment. If the expectations are positive, they will propel the child toward health and well-being (with a placebo effect). If they are negative, they will potentially propel the child toward ill health and the maintenance of functional somatic symptoms (with a nocebo effect) (see also Chapter 12).

Positive expectations were part of each morning's daily ward rounds with Jai, the 14-year-old boy with painful dystonia, weakness and lack of coordination in the legs, and disrupted circadian clock whom we met in Chapters 5 and 11. When the focus of treatment was to stabilize Jai's sleep-he was sleeping only 3-4 hours a night—-the first author (KK) made repeated positive suggestions: 'As your sleep gets better and better, your brain will be able to take a rest from the pain at nighttime, and you will be able to manage the pain better and better during the daytime. We are getting there, bit by bit, step by step.' The suggestions aimed both to maintain Jai's morale and to increase the therapeutic effect of the nighttime medication by activating the placebo effect.

\section{Psychoeducation and Giving the Child (and Parents) Space for Questions}

The manner in which the therapist, at the outset, discusses the neurobiology of the symptoms and integrates this information with the story of the child's symptoms was described in Chapter 3. Over time, the 
child and her therapist, as well as the family and therapist, may need to engage in additional conversations about the formulation, the many different factors (or triggers) that can activate the stress system, or the many ways in which the body responds to threat. Likewise, some neurologists and paediatricians with a special interest in functional somatic symptoms use education about the symptoms as a key element in their medical interventions (Carson et al. 2015).

Johnny, the 9-year-old boy whom we met in Chapter 12, presented with layer upon layer of functional somatic symptoms. He experienced an aha! moment when the therapist explained the formulation: 'I see! They [the danger systems/circles in the stress-system diagram] are trying to protect me, but they keep switching on when they shouldn't. I thought I had cancer and I was going to die.' Two years later, after a relapse of leg paralysis, and after the therapist reiterated the need for Johnny to keep working on his regulation strategies, Johnny exclaimed, 'It's like before. I need to settle down my body when it first starts to switch on. Then I won't get the [functional neurological disorder].'

The following vignette, told by a clinical psychologist, highlights the healing power of psychoeducation - in this case through a lecture (by the first author) about functional somatic symptoms that arise in the context of the body's innate responses to threat (Kozlowska et al. 2015). In the vignette the speaker, Johan, describes his experience (years earlier) of tonic immobility after being shot in the neck by his cousin Thor (the pseudonym refers to Thor, the Norse god who was known to favour violence when he solved problems). In the paediatric context, children presenting with tonic immobility - who habitually activate this innate defence mechanism in response to memories of past maltreatmentmay come to the attention of the neurologist and may be given a diagnosis of non-epileptic seizures (Ratnamohan et al. 2018).

As background for the vignette, Johan, a young clinical psychologist who had just finished his training, was working at his local hospital. One day, his cousin Thor, with whom he was close and whom he had known all his life, assaulted him in front of the hospital. Thor refused 
to tell Johan the reason for the assault. Ten days later, Johan saw Thor passing time outside the hospital and went out to talk to him, hoping to find out what the problem was. Thor was, by then, standing right outside the door, with his back to it. And then, reports Johan:

When I said his name, Thor turned around and lifted his right arm, pointing it at my face. There was a plastic shopping bag around his hand. His hand completed the arc and when it pointed at my face, the bag exploded. From there on everything happened very, very slowly ... I remember falling, like I was slowly sailing through the air. I ended on my back on the icy tarmac in front of the stairs leading up to the door. The thought I had was, 'This is unbelievable. He is killing me. And my desk is in such a mess.' I remember touching my throat with my right hand, and it felt sticky. I looked at it, and it was all red. There were no feelings about these facts. No pain, no sadness, no fear, nothing. Just like some sort of total emotional numbness. Thor watched me for a few seconds, then turned and left. I tried to get up, but I could not move. It felt like I spent an eternity flat on my back waiting for help.

For a long time afterward, I tortured myself with the idea that the shooting communicated the message that I was so worthless and despicable that there was nothing left for Thor to do but to kill me-like you do a rabid dog. He was arrested in his apartment after two hours of very good police work. The first thing he told the officers was that he was proud and relieved that he had eliminated me. He had been told by hundreds of voices (psychotic breakdown as part of a paranoid schizophrenia illness) to kill me because I was the leader of an organization that was out to get him and his daughter. It really was his intention to kill me, and he thought he had succeeded. He still had the gun and one spare cartridge in his pocket. So yes, the body's ancient defences really saved me, by making me look dead. For many years I wondered why I just did not scream or shout to get help or try to get away. I felt worry and shame for not having done anything to save myself that morning. It was not until I attended your lecture in Oslo in 2017 that I understood why my body had responded the way it did on that awful morning. You can't imagine the relief I felt. This ancient defence-tonic immobility-had saved me. 


\section{Changing the Focus of Attention}

Changing the focus of attention can be used by some children in an explicit, conscious, and mindful manner to manage symptoms of pain, fatigue, nausea, discomfort, and so on. Focusing attention on a piece of music, on an artwork/craftwork that is in the process of being completed, on the breath, or on the child's favourite regulation strategyand away from the symptoms - are methods that children commonly choose and that become part of their toolboxes. As we have seen elsewhere, the focus of attention is also managed implicitly in the treatment program via the structure of the program, via the way that conversations are conducted, via the manner in which all interventions are implemented, and via the family intervention, all of which focus attention onto the plans and goals of the day, and away from the symptoms themselves. The following vignette of Jai highlights this principle in the physiotherapy component of the treatment intervention. The vignette describes how the physiotherapist maintained the focus of attention on a particular goal (e.g., reaching a particular distance), on a conversation (e.g., about an unrelated topic), or on some other external stimulus (e.g., the beat of a song), and not on the affected limb or the symptom itself.

Fourteen-year-old Jai presented with multiple functional somatic symptoms-painful fixed dystonia in the neck, motor weakness and lack of coordination in the legs, and a pain-related curve of the body to the left. Toward the end of his admission, when Jai had progressed to mobilizing with walking sticks, his physiotherapist managed the focus of attention very carefully during sessions. Sometimes, when practicing to walk with the sticks, she would chat with Jai about how impressed she was that he had managed to walk up steps earlier in the session, rather than noting or acknowledging in any way that he was dragging his left foot while walking. Any direct focus on the dragging foot would have made the symptom worse.

At other times, when Jai was practicing walking with the sticks, the physiotherapist would ask him-he was very musical - to step to a beat, rhythm, or piece of music. They routinely played a song that Jai loved and that had a moderate tempo, to which he could move step by step. By 
focusing on the song's beat and not on the clearance of his dragging foot, Jai was able to achieve the required clearance in the swing phase of his gait.

Being an adolescent, Jai was also motivated to build up his strength and conditioning using gym equipment. The physiotherapist would focus on and positively reinforce Jai's increasing strength during activities such as a boxing, squats, calf raises, and abdominal crunches. While the explicit focus of attention was Jai's strength, all these activities also involved practice in standing, body control, and positioning. Immersed in the task and focused on his strength, Jai would override the motor patterns associated with his functional neurological disorder. For example, he would complete a boxing set in a standing position. If he had been asked to practice standing for a few minutes on his own, he would have been unable to do so. (This particular material on physiotherapy with Jai is drawn from the first author's materials for her teaching workshops [C Kozlowska 2019]).

\section{Cognitive-Behavioural Interventions}

Children with functional somatic symptoms often suffer from comorbid anxiety. A key feature of their anxiety is a tendency to anticipate negative outcomes (anticipatory anxiety), to appraise situations in a negative way, and to ruminate, catastrophize, and engage in negative self-talk. All these psychological processes, which activate the stress system in a top-down fashion, can trigger, amplify, or maintain functional somatic symptoms (see Chapter 12 for vignettes). Standard cognitive interventions-those known as second-wave cognitive-behavioural therapy (CBT) — are useful in addressing these unhelpful psychological processes.

There are many good resources describing standard CBT interventions that have been developed for working with children (Chansky 2008; Rapee et al. 2000). In addition, Nicole Williams and Sara Zahka provide a detailed description of second-wave CBT in the treatment of children with functional somatic symptoms (Williams and Zahka 2017), and the New South Wales (Australia) Pain Management Network has developed Painbytes, an online program that encourages children to develop self-management for pain skills through physical activity and cognitive approaches (Pain Management Network 2020). For a description of the three waves of CBT, see Online Supplement 15.1. 


\section{Top-Down Mindfulness Interventions}

Jon Kabat-Zinn (2003, p. 145) defined mindfulness as the awareness that emerges through paying attention on purpose, in the present moment, and nonjudgmentally to the unfolding of experience moment by moment'. In our own work with children with functional somatic symptoms, we mostly use bottom-up mindfulness strategies. These strategies focus attention on the body, promote deactivation of the brain stress systems, and do not engage the executive control system (see Chapter 14). It is also possible, however, to use top-down mindfulness strategies. These strategies engage the child's cognitions and thought processes, help the child to employ intentional efforts to increase her attention and awareness capacities (in particular, for better regulation and control of emotions), and activate the executive control system (Guendelman et al. 2017). Topdown regulation strategies have been incorporated into third-wave CBT interventions such as acceptance and commitment therapy (ACT) and dialectical behaviour therapy (DBT).

As noted earlier in the chapter, many children presenting with functional somatic symptoms amplify their symptoms via psychological processes that have become dysfunctional. In this context, some children find that top-down mindfulness interventions-ones that help them observe thoughts and feelings nonjudgmentally and with curiosity and compassion, and that enable them to hold onto memories lightly-are a useful addition to their toolboxes. Some of our favourite top-down mindfulness exercises include the following: asking children to be aware of their feelings and to notice where those feelings reside in their bodies, and placing stressful thoughts and feelings that come to mind onto a leaf floating down a stream, or onto a balloon or into clouds that float away. For resources see Online Supplement 15.1.

Chantal, a 15-year-old girl, had presented to hospital with different functional somatic symptoms-leg weakness and lack of coordination, non-epileptic seizures, and jaw dystonia-on each of three different occasions. In all three admissions the triggering circumstance was some 
combination of a loss, threatened loss, and activation of past memories of loss or trauma. As part of Chantal's therapy, she and her therapist engaged in a trauma-processing intervention (radical exposure tapping) (MacKinnon 2014), processing each memory in turn. During this intervention, the therapist noticed that Chantal was holding onto her memories and not letting them go. After each memory had been processed, so that it no longer caused such a high level of activation in Chantal's body, the therapist asked her to practice-between sessions, holding the memory lightly when it came to mind, 'like a cloud that came and went'. She also suggested that Chantal could verbalize the compassion phrase that came at the end of each tapping sequence, 'I deeply and completely accept myself' to remind her that she could remember the memory lightly and with compassion. Chantal practiced this top-down mindfulness strategy and added it to her toolbox of strategies.

\section{Visualization Exercises}

Some children enjoy and are able to utilize visualization exercises as a means of down-regulating arousal and attaining a relaxed body state. In this scenario it is useful to keep a range of visualization scripts available so that the child can choose those that she likes most. Alternatively, the imagery script can be based on the child's lived experience of attachment figures who are safe and comforting or on her imagination of what is safe and comforting. The script that the therapist will use during the visualization can be co-constructed with the child. The scripts can be recorded onto the child's telephone by the therapist during a session so that the child can use the script independently at bedtime or during scheduled slots for practicing her regulation strategies. For resources see Online Supplement 15.1.

An emerging literature-which is clustered under the construct of attachment security priming - suggests that guided imagery or visualization of a security-enhancing interaction has beneficial outcomes on both subjective and objective (stress-system biomarkers) measures of well-being (Gillath and Karantzas 2019; Norman et al. 2015). 


\section{Hypnosis}

Hypnosis is also a top-down regulation strategy that involves activation of the executive control system and increased top-down control of the brain regions processing pain and body states, deactivation of the brain stress systems, and deactivation of the regions involved in attentional control; the overall effect is to enable the hypnotizable subject to suspend critical judgment and immerse herself in a task, while reducing awareness of alternatives (Jiang et al. 2017). A growing evidence base supports the use of hypnosis in treating children with functional somatic symptoms (see commentary by the third author $[\mathrm{HH}]$ in 'Twisted in Pain: The Multidisciplinary Treatment Approach to Functional Dystonia' [Khachane et al. 2019]). Hypnosis can be used in two different ways: as therapeutic suggestions that are part of ordinary conversation and as a formal procedure involving a formal induction process.

Therapeutic suggestions are part of all therapeutic conversations. In this context, the therapist uses language in a way that makes positive suggestions, promotes hope, and harnesses the placebo effect in a maximal way. Both the first and third authors have been influenced by the work of Milton Erickson, an American psychiatrist who specialized in medical hypnosis and family therapy, and who saw 'deeds [as the] offspring of hope and expectancy' (Erickson 1954, p. 261; Haley 1973), meaning that the individuals' hopes and expectations have a profound influence on their actions. Positive hopes and expectations lead into positive actions, and negative hopes and expectations lead into negative actions. Using words, metaphors, and suggestion to put down stepping stones and create a path ahead for each patient, Erickson hoped to steer the patients toward healthy actions and healthy future outcomes. In the same way, all members of our multidisciplinary teams integrate positive suggestions - suggestions that point the child in the right directioninto our conversations.

In a ward conversation we might say something like, 'How exciting that you were able to do the slow-breathing exercise all by yourself last night. You really have the skills you need-don't you! As you practice your breathing exercise more and more, your breathing rate will get slower and 
slower, and your pain will get less and less-even in periods of the day when you are not practicing—all by itself. Isn't that interesting!'

When used more formally, with individuals who are hypnotizable, a formal induction process is used to help the child enter the hypnotic state, a brain state involving activation of the executive control system and increased connectivity between the executive control system and brain regions processing information about body state, coupled with deactivation of attention control regions. Children who are able to enter the hypnotic state-to “"switch" connectivity patterns' (Jiang et al. 2017, p. 4088) — are then able to respond to verbal suggestions to elicit pronounced changes in pain perception, level of arousal, and motor and sensory function.

Some children enjoy hypnosis as a means of decreasing arousal and practicing a state of relaxation accompanied by vivid imagery. Once they are able to do self-hypnosis - they practice using an audio recording of a hypnosis session by their hypnotherapist - they can integrate this skill into the program that they take home or use it to help them fall asleep at night or to settle themselves if they wake up at night. Some children are able to use self-hypnosis to manage their chronic pain. As described in the following vignette, the first author's team also used hypnosis alongside physiotherapy and occupational therapy to help mobilize - in essence, straighten out - a boy with fixed dystonia and comorbid chronic pain (see Chapter 5 for details of Jai's presentation).

Jai, the 14-year-old boy we met in Chapter 5, presented with a painful fixed dystonia in the neck, a pain-related twisting of his body to the left, with the consequence that, when sitting in the wheelchair, he twisted over the side in an arc. He had also lost power and coordination in his legs. $\mathrm{He}$ experienced constant pain, and any attempt at movement caused contracture of the muscles in the neck that were unbearably painful. Jai's pain prevented all physiotherapy and occupational therapy interventions that would assist him to mobilize him or to begin the process of correcting his body posture. The breakthrough came when it became apparent that Jai was highly hypnotizable. Hypnosis was added to Jai's treatment program to manage the pain. With hypnotic suggestions, Jai was able to disconnect 
from the pain and was able to imagine his body bending and moving like a reed or a tree. While Jai imagined the movement, the physiotherapist would reposition him into a straighter posture. In addition, the hypnotherapist made suggestions that, with time, Jai's brain would readjust and that his body would be straight and tall like a young tree.

After completing the program, Jai continued to use the hypnosis strategies with the assistance of audio recordings that he took home. For a detailed account of the intervention with Jai, see Khachane and colleagues (2019). For references to hypnosis in working with children, see Online Supplement 1.3.

\section{Pain Coping Skills}

We include pain coping skills as a separate heading because pain is a common symptom in functional presentations. Pain coping skills were developed in the 1980s by therapists working in the second-wave CBT tradition for use with patients with chronic medical conditions. At that time these skills included the following: involving oneself in distracting activities; attempting to ignore or reinterpret pain sensations; changing activity level; praying or hoping; and use of calming self-statements (Keefe et al. 1987). Later on, as the importance of pain catastrophizing became better understood, cognitive strategies also came to be used to manage that catastrophizing. More recently, both bottom-up (see Chapter 14) and top-down (this chapter) mindfulness strategies have been added to the pain coping strategies that are taught to patients with chronic pain or with certain medical conditions. For a current review of pain coping skills and strategies used with children with chronic pain and their parents, see Harrison et al. (2019).

Jai, the 14-year-old boy with a painful dystonia, often used distraction as a pain-management strategy. After experimenting with a range of activities, he decided that what worked especially well was to distract himself from the pain by playing his favourite songs on the keyboard or by composing new songs with the help of the keyboard. 
In this chapter we have touched upon some of the cognitive and psychological interventions that pertain to the mind level of operations and that can be integrated by the clinician into the systemic intervention for functional somatic symptoms. These top-down interventions can be integrated alongside interventions on other system levels to help the child shift her stress system back to a more regulated state, one that supports health and well-being and is incompatible with functional somatic symptoms.

\section{References}

Benedetti, F. (2013). Placebo and the New Physiology of the Doctor-Patient Relationship. Physiological Reviews, 93, 1207-1246.

Carson, A., Lehn, A., Ludwig, L., \& Stone, J. (2015). Explaining Functional Disorders in the Neurology Clinic: A Photo Story. Practical Neurology, 16, 56-61.

Chansky, T. E. (2008). Freeing Your Child from Negative Thinking: Powerful, Practical Strategies to Build a Lifetime of Resilience, Flexibility, and Happiness. Cambridge, MA: Da Capo Press.

Erickson, M. (1954). Pseudo-orientation in Time as a Hypnotherapeutic Procedure. Journal of Clinical and Experimental Hypnosis, 2, 261-283.

Gillath, O., \& Karantzas, G. (2019). Attachment Security Priming: A Systematic Review. Current Opinion in Psychology, 25, 86-95.

Guendelman, S., Medeiros, S., \& Rampes, H. (2017). Mindfulness and Emotion Regulation: Insights from Neurobiological, Psychological, and Clinical Studies. Frontiers in Psychology, 8, 220.

Haley, J. (1973). Uncommon Therapy: The Psychiatric Techniques of Milton H. Erickson, M.D. New York: Norton.

Harrison, L. E., Pate, J. W., Richardson, P. A., Ickmans, K., Wicksell, R. K., \& Simons, L. E. (2019). Best-Evidence for the Rehabilitation of Chronic Pain Part 1: Pediatric Pain. Journal of Clinical Medicine, 8, E1267.

Jiang, H., White, M. P., Greicius, M. D., Waelde, L. C., \& Spiegel, D. (2017). Brain Activity and Functional Connectivity Associated with Hypnosis. Cerebral Cortex, 27, 4083-4093. 
Kabat-Zinn, J. (2003). Mindfulness-Based Interventions in Context: Past, Present, and Future. Clinical Psychology: Science and Practice, 10, 144-156. Keefe, F. J., Caldwell, D. S., Queen, K. T., Gil, K. M., Martinez, S., Crisson, J. E., et al. (1987). Pain Coping Strategies in Osteoarthritis Patients. Journal of Consulting and Clinical Psychology, 55, 208-212.

Khachane, Y., Kozlowska, K., Savage, B., McClure, G., Butler, G., Gray, N., et al. (2019). Twisted in Pain: The Multidisciplinary Treatment Approach to Functional Dystonia. Harvard Review of Psychiatry, 27, 359-381. https:// pubmed.ncbi.nlm.nih.gov/31714467/.

Koyama, T., McHaffie, J. G., Laurienti, P. J., \& Coghill, R. C. (2005). The Subjective Experience of Pain: Where Expectations Become Reality. Proceedings of the National Academy of Sciences of the United States of America, 102, 12950-12955.

Kozlowska, K. (2019, February). Making Sense of Somatic Symptoms: The Neurobiology of Bodytalk. Workshop, Children's Hospital at Westmead, Sydney, Australia.

Kozlowska, K., Walker, P., McLean, L., \& Carrive, P. (2015). Fear and the Defense Cascade: Clinical Implications and Management. Harvard Review of Psychiatry, 23, 263-287. https://www.ncbi.nlm.nih.gov/pmc/articles/ PMC4495877/.

MacKinnon, L. (2014). Deactivating the Buttons: Integrating Radical Exposure Tapping with a Family Therapy Framework. Australian and New Zealand Journal of Family Therapy, 35, 244-260.

Norman, L., Lawrence, N., Iles, A., Benattayallah, A., \& Karl, A. (2015). Attachment-Security Priming Attenuates Amygdala Activation to Social and Linguistic Threat. Social Cognitive and Affective Neuroscience, 10, 832-839.

Pain Management Network. (2020). Painbytes. https://www.aci.health.nsw.gov. au/chronic-pain/painbytes.

Posner, M. I. (2012). Attention in a Social World. New York: Oxford University Press.

Rapee, R., Wignall, A., Hudson, J., \& Schniering, C. A. (2000). Treating Anxious Children and Adolescents. Oakland, CA: New Harbinger Publications.

Ratnamohan, L., MacKinnon, L., Lim, M., Webster, R., Waters, K., Kozlowska, K., et al. (2018). Ambushed by Memories of Trauma: Memory-Processing Interventions in an Adolescent Boy with Nocturnal Dissociative Episodes. Harvard Review of Psychiatry, 26, 228-236.

Wager, T. D., \& Atlas, L. Y. (2015). The Neuroscience of Placebo Effects: Connecting Context, Learning and Health. Nature Reviews Neuroscience, 16, 403-418. 
Williams, L. M. (2016). Defining Biotypes for Depression and Anxiety Based on Large-Scale Circuit Dysfunction: A Theoretical Review of the Evidence and Future Directions for Clinical Translation. Depression and Anxiety, 34, 9-24. Williams, S. E., \& Zahka, N. E. (2017). Treating Somatic Symptoms in Children and Adolescents. New York: Guilford Press.

Open Access This chapter is licensed under the terms of the Creative Commons Attribution-NonCommercial-NoDerivatives 4.0 International License (http://creativecommons.org/licenses/by-nc-nd/4.0/), which permits any noncommercial use, sharing, distribution and reproduction in any medium or format, as long as you give appropriate credit to the original author(s) and the source, provide a link to the Creative Commons license and indicate if you modified the licensed material. You do not have permission under this license to share adapted material derived from this chapter or parts of it.

The images or other third party material in this chapter are included in the chapter's Creative Commons license, unless indicated otherwise in a credit line to the material. If material is not included in the chapter's Creative Commons license and your intended use is not permitted by statutory regulation or exceeds the permitted use, you will need to obtain permission directly from the copyright holder.

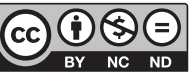

